\title{
Nucleolar Structure by Atomic Force Microscopy
}

María de Lourdes Segura-Valdez ${ }^{1}$, Dircé Pineda-Vázquez ${ }^{1}$, Paulina Mendoza von der Borch ${ }^{1}$, Luis Felipe Jiménez-García ${ }^{1 *}$

1. Cell Nanobiology Laboratory and Electron Microscopy Laboratory, Department of Cell Biology, Faculty of Sciences, National Autonomous University of Mexico (UNAM). Circuito Exterior CU 04510 Coyoacán, Cd Mx, México.

* Corresponding author: luisfelipe_jimenez@ ciencias.unam.mx

The nucleolus is involved in ribosome biogenesis and functions as aging, cell cycle, stress, etc. Studies using light and electron microscopy and analytical techniques indicated that it is composed by the ultrastructural elements named fibrillar centers, dense fibrillar component and granular component and around seven gundread 700 proteins, the ribosomal genes (rDNA), and several types of RNA as pre-rRNA, rRNA, and UsnoRNAs.

Nucleolar elements disperse during cell division. In prophase the nucleolus is breaking down and it is assembled during telophase from nucleolar organized regions (NOR) first described in the earlies 1930's and fusion of prenucleolar bodies (PNBs) during a conserved cell process called nucleologenesis [1].

The presence of nucleoli in parasites as Giardia lamblia, Trypanosoma cruzi and Entamoeba histolytica [2-4], and the persistence of nucleoli during nucleologenesis in cells of G. lamblia and T. cruzi [5-6], suggests that nucleolus is a conserved structure in eukaryotes. However, data at the nanoscales using atomic force microscopy (AFM) is lacking.

Here we used samples of Ginkgo biloba and semithin section prepared as for transmission electron microscopy, mounted on glass slides and scanned by AFM in contact mode [7].

Results show that dense fibrillar component is distinguished from granular component. The profiles of nucleoli are different from compact chromatin (Figure 1).

Our results may help to distinguish nucleolar components ( Supported by DGAPA-UNAM IN217917; PAPIME PE213916; CONACyT 180835. We thank Saraí Cruz-Gómez for technical assistance. 


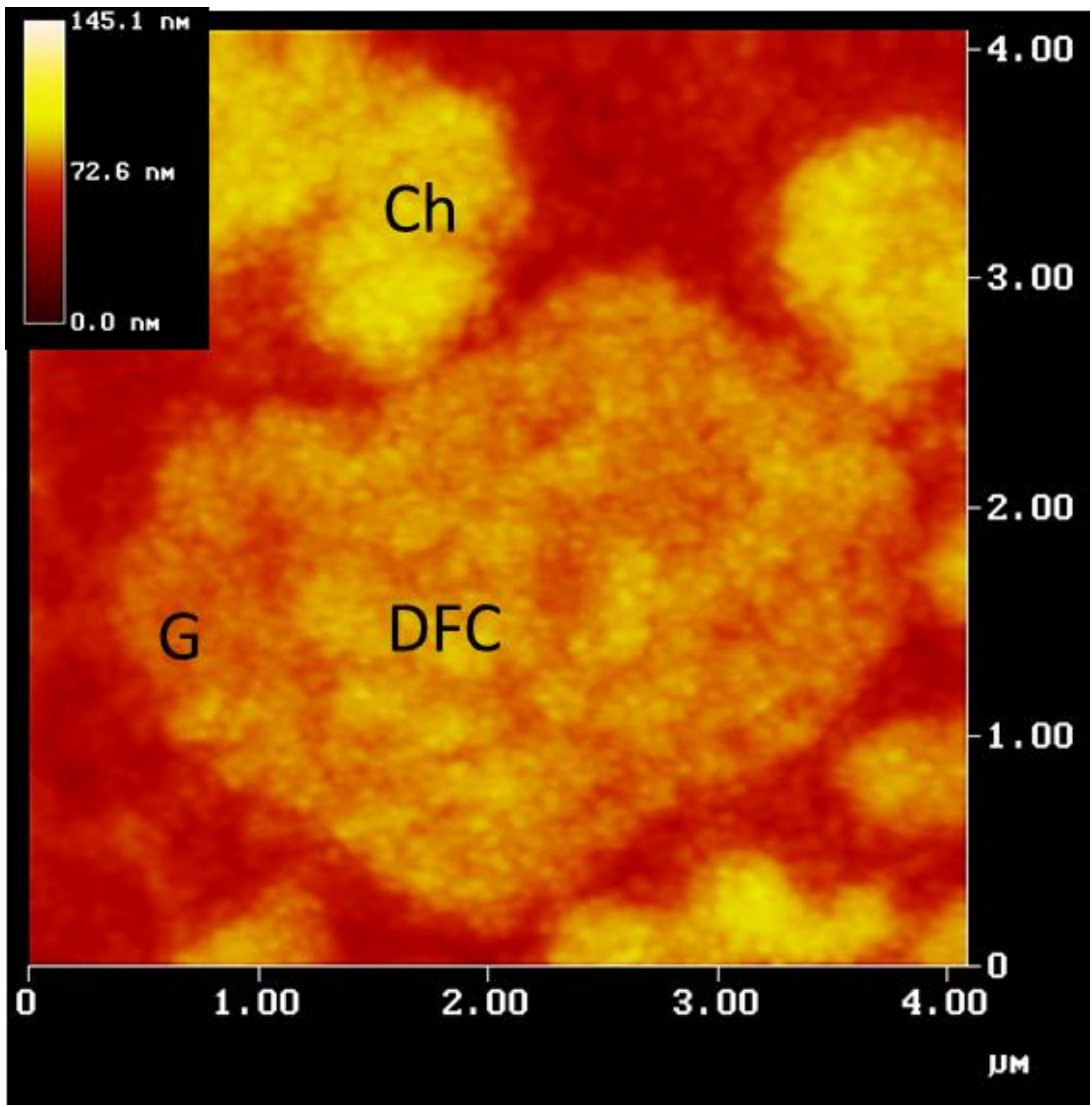

Figure 1. Atomic force micrograph of the nucleolus of Ginko biloba leaves. The dense fibrilar component (DFC) is distinguished from granular component (G). Ch, cromatin.

\section{References}

[1] D Hernandez-Verdun et al. (2010) Histoche Cell Biol 129, 13.

[2] LF Jiménez-García et al. (2008) Int J Parasitol 38, 1297.

[3] G López-Velázquez (2005) et al. Microsc Microanal 11, 293.

[4] C Vázquez-Echeverría et al. (2009) TIP Rev Esp Cien Quim-Biol 12, 34.

[5] R Lara-Martínez et al. (2016) Anat Rec 299, 549.

[6] T Nepomuceno-Mejía et al. (2016) Microsc Microanal 22, 621.

[7] ML Segura-Valdez et al. (2018) Histochem. Cell Biol 150, 521. 